\title{
FAKTOR-FAKTOR YANG MEMPENGARUHI DAYA TAHAN MAHASISWA TEKNIK SIPIL UIB DALAM MEMPERTAHANKAN STUDINYA
}

\author{
Mahfuz Hudori ${ }^{1 \S}$ \\ ${ }^{1}$ Prodi Teknik Sipil Universitas Internasional Batam [Email: mahfuz@uib.ac.id] \\ ${ }^{\S}$ Corresponding Author
}

\begin{abstract}
Linear regression model cannot be used to analyze the relationship between survival time and independent variables, it is because the linear regression model is not able to handle censored data. Regression can be used to analyze survival data is cox proportional hazard regression. This research studies factors that influence study time drop out of Civil Engineering students at Universitas International Batam using the cox proportional hazard regression model approach. The independent variable that influenced study time drop out of Civil Engineering students at Universitas International Batam was the Cumulative Achievement Index and Work Status.
\end{abstract}

Keywords: survival analysis, drop out, cox proportional hazard

\section{PENDAHULUAN}

Universitas Internasional Batam (UIB) setiap tahunnya menerima mahasiswa baru dengan latar belakang pendidikan dan asal daerah yang berbeda dari berbagai provinsi di Indonesia. Mahasiswa yang diterima kemudian mengikuti pembelajaran di program studi yang telah dipilih. Selama proses pembelajaran berlangsung, kampus memberlakukan evaluasi untuk membuat kebijakan terhadap akademik mahasiswa. Penerapan kebijakan tersebut berdampak pada status mahasiswa, yaitu dinyatakan aktif sebagai mahasiswa atau tidak aktif (pemberhentian).

Proses pembelajaran sampai dengan evaluasi akademik dan keluarnya kebijakan berupa status tidak aktif atau pemberhentian mahasiswa merupakan contoh survival time. Di dalam statistika, survival time dapat dinyatakan sebagai jangka waktu sampai terjadinya suatu kejadian (Gayatri, 2014). Adapun analisis statistik yang sesuai untuk data survival adalah dengan menggunakan analisis survival (Kleinbaum \& Klein, 2011). Menganalisis hubungan antara survival time dengan peubah bebasnya tidak dapat dilakukan dengan menggunakan model regresi linier pada umumnya, hal tersebut dikarenakan model regresi linier tidak mampu menangani data yang bersifat tersensor. Model regresi yang sering digunakan untuk menganalisis data survival yaitu regresi cox proportional hazard. Penggunaan regresi cox proportional hazard telah banyak diaplikasikan di berbagai bidang, di antaranya untuk menduga faktor-faktor yang memengaruhi lama mencari kerja (Sudana et al., 2013), mengidentifikasi faktor-faktor yang mempengaruhi laju tamat mahasiswa jurusan matematika universitas andalas (Marisa et al., 2017) dan penerapannya pada data sintasan pasien diabetes melitus (Dewi et al., 2018). Pendekatan lain dalam menganalisis data survival adalah dengan menggunakan regresi logistik biner, yaitu mengubah peubah respon pada regresi survival ke bentuk biner. Regresi cox proportional hazard merupakan model yang cukup handal (robust) dalam memodelkan data survival karena menghasilkan estimasi parameter yang tidak jauh berbeda dengan model parametrik (Kleinbaum \& Klein, 2011). Penggunaan analisis regresi logistik biner dalam memodelkan data ketahanan (survival) juga menghasilkan nilai parameter yang tidak jauh berbeda dengan analisis menggunakan model regresi cox proportional hazard (Ratnaningsih et al., 2019). 
Penelitian ini dilakukan untuk mengidentifikasi peubah-peubah yang berpengaruh terhadap ketahanan mahasiswa dalam mempertahankan studinya di Program Studi Teknik Sipil Universitas Internasional Batam (UIB).

\section{METODE PENELITIAN}

\subsection{Data Penelitian}

Data yang akan digunakan dalam penelitian ini adalah data mahasiswa baru Program Studi Teknik Sipil Universitas Internasional Batam (UIB) di Tahun Akademik 2015/2016 yang diamati sampai dengan Semester Genap Tahun Akademik 2018/2019. Mahasiswa yang tidak mengalami putus studi atau tetap aktif selama waktu pengamatan dinyatakan sebagai data tersensor dan data tersensor tersebut masuk ke dalam definisi data tersensor tipe I.

Peubah respon yang menjadi perhatian yaitu waktu pembelajaran sampai dengan evaluasi akademik dan keluarnya kebijakan berupa pemberhentian atau status tidak aktif mahasiswa. Beberapa peubah bebas yang digunakan dalam penelitian ini adalah (Hudori, 2016) dan (Chandra \& Rohmaniah, 2019):

Tabel 1 Rincian peubah bebas yang digunakan

\begin{tabular}{|c|l|l|}
\hline No & Peubah & Kategori \\
\hline 1 & $\mathrm{X}_{1}$ (Jenis kelamin) & $\begin{array}{l}1=\text { Laki-laki } \\
2=\text { Perempuan }\end{array}$ \\
\hline 2 & $\mathrm{X}_{2}$ (Biaya Kuliah) & $\begin{array}{l}1=\text { Reguler } \\
2=\text { Beasiswa }\end{array}$ \\
\hline 3 & $\mathrm{X}_{3}$ (IPK) & $\begin{array}{l}1=\mathrm{x}>3,00 \\
2=2,75 \leq \mathrm{x} \leq 3,00 \\
3=\mathrm{x}<2,75\end{array}$ \\
\hline 4 & $\mathrm{X}_{4}$ (Status bekerja) & $\begin{array}{l}1=\text { Tidak bekerja } \\
2=\text { Bekerja }\end{array}$ \\
\hline
\end{tabular}

IPK : Indeks Prestasi Kumulatif

\subsection{Metode Analisis Data}

Langkah-langkah yang dilakukan dalam melakukan analisis daya tahan mahasiswa dalam mempertahankan studinya di Program Studi Teknik Sipil Universitas Internasional Batam (UIB) adalah sebagai berikut:

(i) Melakukan pemodelan regresi cox proportional hazard

Model regresi cox proporsional hazard yang digunakan adalah sebagai berikut:

$$
h(t)=h_{0}(t) \exp \left(\sum_{i=1}^{r} \beta_{i} X_{i}\right)
$$

dengan :

t : waktu hingga suatu kejadian terjadi (tidak aktif atau putus studi)

$\mathrm{h}_{0}(\mathrm{t})$ : fungsi dasar hazard (baseline hazard function) yang tidak tergantung pada peubah bebas $\mathrm{X}$

$\beta$ : koefisien regresi

$\mathrm{X}$ : peubah bebas (kovariat)

(ii) Pengujian parameter model regresi cox proportional hazard dan model regresi cox proportional hazard

Pengujian parameter model dilakukan dengan menggunakan dua cara, yaitu dengan uji nisbah kemungkinan (likelihood ratio test) dan uji wald (Imran et al., 2013).

(iii) Memeriksa asumsi proportional hazard

Pemeriksaan asumsi proportional hazard untuk masing-masing peubah bebas menggunakan uji goodness of fit (GOF) (Muller, 2004; Verweij et al., 1998).

(iv) Melakukan seleksi peubah bebas

Pemilihan peubah bebas pada penelitian ini menggunakan seleksi forward, yaitu memasukkan peubah bebas yang merupakan prediktor terbaik untuk dimasukkan ke dalam model dengan cara menambahkan peubah bebas tersebut satu demi satu dalam setiap langkahnya.

Proses analisis pada penelitian ini menggunakan bantuan software SPSS v.23 dan $R$.

\section{HASIL DAN PEMBAHASAN}

\subsection{Deskripsi Data}

Mahasiswa baru yang diterima di Program Studi Teknik Sipil Universitas Internasional Batam (UIB) pada tahun akademik 2015/2016 berjumlah 57 orang. Dari data tersebut diperoleh data tersensor sebanyak 50 data dan yang tidak tersensor sebanyak 7 data. Dari data mahasiswa tersebut diperoleh jumlah responden perempuan sebanyak 19 orang $(33,33 \%)$ dan 38 orang $(66,67 \%)$ lainnya merupakan laki-laki. Mahasiswa yang diterima melalui program beasiswa sebanyak 24 orang $(42,11 \%)$ dan 33 orang $(57,89 \%)$ lainnya merupakan mahasiswa reguler. Sampai dengan Tahun Akademik 2018/2019, mahasiswa yang memperoleh 
Indeks Prestasi Kumulatif (IPK) lebih dari 3,00, antara 2,75 - 3,00 dan kurang dari 2,75 berturut-turut sebanyak 45 orang $(78,95 \%), 8$ orang $(14,04 \%)$ dan 4 orang $(7,02 \%)$. Sebagian besar mahasiswa Teknik Sipil Universitas Internasional Batam (UIB) telah bekerja sebelum lulus, hal ini tercermin dari jumlah mahasiswa yang bekerja sebanyak 55 orang $(96,49 \%)$ dan 2 orang $(3,51 \%)$ lainnya tidak bekerja.

\subsection{Analisis Regresi Cox Proportional Hazard}

Analisis data menggunakan alat bantu software SPSS menghasilkan luaran sebagai berikut (Tabel 2):

Tabel 2. Hasil analisis regresi cox proportional hazard

\begin{tabular}{|c|c|c|c|c|c|}
\hline Peubah & Koefisien & $\begin{array}{c}\text { Galat } \\
\text { baku }\end{array}$ & Wald & $\mathrm{db}$ & Nilai- $p$ \\
\hline $\mathrm{X}_{1(1)}$ & 0,238 & 0,976 & 0,059 & 1 & 0,808 \\
\hline $\mathrm{X}_{2(1)}$ & $-0,376$ & 0,860 & 0,191 & 1 & 0,662 \\
\hline $\mathrm{X}_{3}$ & & & 6,064 & 2 & 0,048 \\
\hline $\mathrm{X}_{3(1)}$ & 2,507 & 1,056 & 5,630 & 1 & 0,018 \\
\hline $\mathrm{X}_{3(2)}$ & 0,726 & 1,012 & 2,908 & 1 & 0,088 \\
\hline $\mathrm{X}_{4}$ & $-2,684$ & 1,290 & 4,325 & 1 & 0,038 \\
-2 Log Likelihood $=46,904$, derajat bebas $(\mathrm{db})=5$, \\
Chi-square $\left(\chi^{2}\right)=13,199, p$-value $=0.022$
\end{tabular}

Hasil analisis regresi cox proportional hazard (Tabel 2) menghasilkan nilai -2Log Likelihood $=46,904$, nilai $\chi^{2}=13,199$ dan derajat bebas $(\mathrm{db})=5$. Nilai $\chi^{2}=13,199>$ $\chi_{\mathrm{db}=5}^{2}=12,59$ dan nilai- $p=0.022<\alpha=5 \%$ menunjukkan bahwa secara simultan diperoleh informasi bahwa di dalam model tersebut terdapat minimal satu peubah bebas yang mempengaruhi ketahanan mahasiswa dalam mempertahankan studinya di Program Studi Teknik Sipil Universitas Internasional Batam (UIB).

Pengujian secara parsial menggunakan uji Wald (Tabel 2) dengan taraf $\alpha=5 \%$ diperoleh nilai- $p$ untuk peubah $\mathrm{X}_{1(1)}$ (Jenis kelamin) sebesar $0,808, X_{2(1)}$ (Biaya Kuliah) sebesar $0,662, X_{3}$ (IPK) sebesar 0,048, dan $X_{4}$ (Status Bekerja) sebesar 0,038 . Untuk peubah yang memiliki nilai- $p$ lebih kecil dari $\alpha=5 \%$ diperoleh kesimpulan bahwa $\mathrm{X}_{3}$ (IPK) dan $\mathrm{X}_{4}$ (Status Bekerja) merupakan peubah bebas yang nyata mempengaruhi ketahanan mahasiswa dalam mempertahankan studinya di Program Studi Teknik Sipil Universitas Internasional Batam (UIB). Sedangkan dua peubah lainnya, yaitu peubah $X_{1(1)}$ (Jenis kelamin) dan $X_{2(1)}$ (Biaya kuliah) tidak berpengaruh nyata terhadap ketahanan mahasiswa dalam mempertahankan studinya di Program Studi Teknik Sipil Universitas Internasional Batam (UIB) pada taraf $\alpha=5 \%$.

Besarnya peluang untuk tidak aktif bagi mahasiswa Program Studi Teknik Sipil Universitas Internasional Batam (UIB) dapat diketahui melalui grafik fungsi survival berikut ini (Gambar 1):

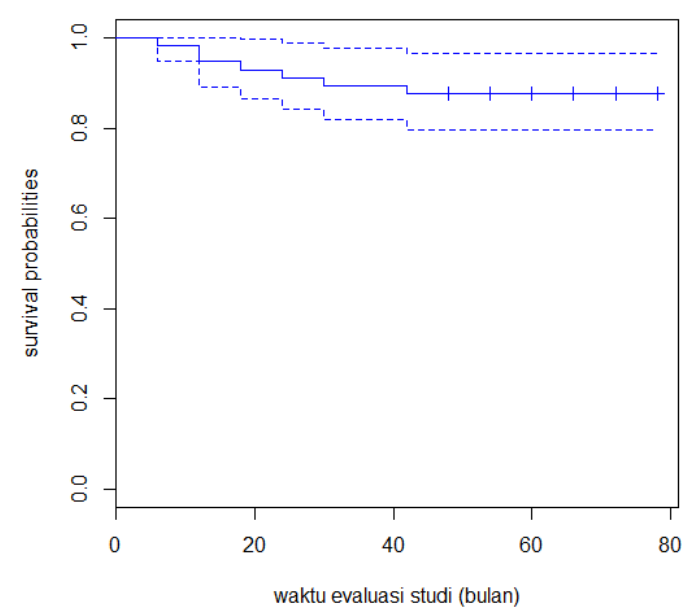

Gambar 1. Fungsi survival waktu studi mahasiswa Teknik Sipil

Peluang mahasiswa untuk tidak aktif atau putus studi dari Program Studi Teknik Sipil Universitas Internasional Batam (UIB) (Gambar 1) semakin rendah setelah melewati pembelajaran selama 40 bulan (6 semester) dan sangat tinggi peluangnya untuk tidak aktif atau putus studi pada saat pembelajaran berjalan selama $1-24$ bulan (4 semester).

\subsection{Uji Asumsi Proportional Hazard}

Peubah bebas yang digunakan dalam analisis survival harus memenuhi asumsi proportional hazard. Hasil pengujian asumsi proportional hazard menggunakan uji goodness of fit dapat dilihat pada Tabel 3.

Tabel 3. Hasil uji asumsi proportional hazard

\begin{tabular}{|l|c|c|c|}
\hline Peubah & rho $(\boldsymbol{\rho})$ & Chisq & $\boldsymbol{p}$ \\
\hline $\mathbf{X}_{\mathbf{1}(\mathbf{1})}$ & 0,213 & 0,476 & 0,490 \\
\hline $\mathbf{X}_{\mathbf{2}(\mathbf{1})}$ & $-0,479$ & 1,850 & 0,174 \\
\hline $\mathbf{X}_{\mathbf{3 ( 1 )}}$ & $-0,139$ & 0,129 & 0,720 \\
\hline $\mathbf{X}_{\mathbf{3 ( 2 )}}$ & $-0,122$ & 0,092 & 0,762 \\
\hline $\mathbf{X}_{\mathbf{4}}$ & $-0,013$ & 0,002 & 0,967 \\
\hline
\end{tabular}


Hasil uji asumsi proportional hazard (Tabel 3) untuk peubah $\mathrm{X}_{4}$ (Status bekerja) diperoleh nilai rho $=-0,013, \chi^{2}=0,002$ dan nilai- $p=0,967$. Dengan nilai $\chi^{2}=0,002<$ $\chi_{d b=1}^{2}=3.84$ dan nilai $-p=0,967>\alpha=5 \%$, dapat disimpulkan bahwa tidak terdapat korelasi antara residual schoenfeld dan rank waktu/proses pembelajaran sampai dengan evaluasi akademik dan keluarnya kebijakan berupa pemberhentian atau status tidak aktif mahasiswa. Tidak adanya korelasi antara residual schoenfeld dan rank waktu/proses pembelajaran sampai dengan evaluasi akademik dan keluarnya kebijakan berupa pemberhentian atau status tidak aktif mahasiswa mengindikasikan bahwa peubah $\mathrm{X}_{4}$ (Status bekerja) telah memenuhi asumsi proportional hazard. Berdasarkan analisis yang telah dilakukan, dapat dikatakan juga bahwa peubah lainnya telah memenuhi asumsi proportional hazard.

\subsection{Pemilihan Peubah Bebas}

Pemilihan peubah bebas menggunakan metode forward menghasilkan peubah-peubah yang secara nyata memberikan pengaruh terhadap ketahanan mahasiswa dalam mempertahankan studinya di Program Studi Teknik Sipil Universitas Internasional Batam (UIB). Peubah-peubah tersebut dapat dilihat di bawah ini (Tabel 4):

Tabel 4. Hasil seleksi peubah bebas menggunakan metode forward

\begin{tabular}{|l|c|c|c|c|c|c|}
\hline $\begin{array}{l}\text { Pe- } \\
\text { ubah }\end{array}$ & $\begin{array}{c}\text { Koef- } \\
\text { isien }\end{array}$ & $\begin{array}{c}\text { Galat } \\
\text { baku }\end{array}$ & Wald & db & $\begin{array}{c}\text { Nilai- } \\
\boldsymbol{p}\end{array}$ & $\begin{array}{c}\text { Rasio } \\
\text { Hazard }\end{array}$ \\
\hline $\mathrm{X}_{3}$ & & & 7,161 & 2 & 0,028 & \\
\hline $\mathrm{X}_{3(1)}$ & 2,633 & 1,005 & 6,859 & 1 & 0,009 & 13,909 \\
\hline $\mathrm{X}_{3(2)}$ & 1,779 & 1,000 & 3,166 & 1 & 0,075 & 5,926 \\
\hline $\mathrm{X}_{4(1)}$ & $-2,637$ & 1,231 & 4,590 & 1 & 0,032 & 0,072 \\
\hline
\end{tabular}

Berdasarkan Tabel 4, diperoleh persamaan model regresi cox proportional hazard sebagai berikut :

$$
\begin{aligned}
\mathrm{h}(\mathrm{t})= & \mathrm{h}_{0}(\mathrm{t}) \exp \left[2,633 \mathrm{X}_{3(1)}+1,779 \mathrm{X}_{3(2)}-\right. \\
& \left.2,637 \mathrm{X}_{4(1)}\right]
\end{aligned}
$$

Peubah $X_{3(1)}\left(\right.$ IPK < 2,75) dan $X_{3(2)}($ IPK $=$ 2,75 - 3,00) berturut-turut memiliki koefisien sebesar 2,633 dan 1,779. Nilai koefisien yang positif mengindikasikan bahwa risiko untuk tidak melanjutkan studi bagi mahasiswa yang memiliki IPK tersebut sangat tinggi dibandingkan dengan mahasiswa yang IPK-nya lebih dari 3,00. Dengan kata lain risiko mahasiswa yang memiliki IPK $<2,75$ akan putus studi dari Prodi Teknik Sipil UIB 13,909 kali dari mahasiswa yang ber-IPK lebih dari 3,00 dan risiko mahasiswa yang memiliki IPK = 2,75 - 3,00 akan putus studi dari Prodi Teknik Sipil UIB 5,926 kali dari mahasiswa yang berIPK lebih dari 3,00.

Peubah $\mathrm{X}_{4(1)}$ (Mahasiswa bekerja) memiliki koefisien sebesar $-2,637$. Nilai koefisien yang negatif menunjukkan bahwa risiko mahasiswa yang bekerja lebih rendah untuk putus studi. Risiko mahasiswa yang bekerja akan putus studi 0,072 kali dari mahasiswa yang tidak bekerja.

\section{KESIMPULAN DAN SARAN}

\subsection{Kesimpulan}

Hasil analisis yang dilakukan memberikan kesimpulan sebagai berikut :

a. Peubah yang mempengaruhi ketahanan mahasiswa dalam mempertahankan studinya di Program Studi Teknik Sipil Universitas Internasional Batam (UIB) adalah peubah $\mathrm{X}_{3}$ (IPK) dan $\mathrm{X}_{4}$ (Status Bekerja).

b. Hasil pemodelan survival time terhadap peubah yang berpengaruh nyata menggunakan regresi cox proportional hazard adalah sebagi berikut :

$$
\begin{aligned}
\mathrm{h}(\mathrm{t})= & \mathrm{h}_{0}(\mathrm{t}) \exp \left[2,633 \mathrm{X}_{3(1)}+1,779 \mathrm{X}_{3(2)}\right. \\
& \left.-2,637 \mathrm{X}_{4(1)}\right]
\end{aligned}
$$

\subsection{Saran}

Model yang dibangun pada penelitian ini masih dapat dikembangkan lagi dengan menambahkan bentuk distribusi survival timenya dengan mempertimbangkan efek spasial (wilayah) yaitu asal daerah para mahasiswa.

\section{DAFTAR PUSTAKA}

Chandra, N. E., \& Rohmaniah, S. A. (2019).

Analisis Survival Model Regresi

Parametrik Lama Studi Mahasiswa. Jurnal

Matematika, 9(1), 01.

https://doi.org/10.24843/jmat.2019.v09.i01. p106

Dewi, I. A. P. R., Suciptawati, N. L. P., \&

Tastrawati, N. K. T. (2018). Aplikasi

Regresi Cox Proportional Hazard Pada 
Sintasan Pasien Diabetes Melitus. E-Jurnal Matematika, 7(3), 278.

https://doi.org/10.24843/mtk.2018.v07.i03. p215

Gayatri, D. (2014). Mengenal Analisis Ketahanan (Survival Analysis). Jurnal Keperawatan Indonesia, 9(1), 36-40. https://doi.org/10.7454/jki.v9i1.158

Hudori, M. (2016). Analisis Daya Tahan Menunggu Kelahiran Anak Pertama di Provinsi Lampung [IPB University]. https://repository.ipb.ac.id/jspui/bitstream/1 23456789/80508/1/2016mhu.pdf

Imran, F., Susetyo, B., Wigena, A. H., \& . (2013). Identifikasi Faktor-Faktor Yang Berhubungan Dengan Mahasiswa Putus Kuliah Di Ipb Angkatan 2008 Menggunakan Analisis Survival. Xplore, 1(2), 2-7.

https://doi.org/10.29244/xplore.v1i2.12404

Kleinbaum, D. G. D., \& Klein, M. (2011). Survival Analysis: A Self-Learning Text, Third Edition (Statistics for Biology and Health). In Biometrical Journal. https://doi.org/10.1016/B978-0-12-3876676.00013-0

Marisa, Yozza, H., \& Maiyastri. (2017). Model Regresi Cox Proportional Hazard Pada Laju Tamat Mahasiswa Jurusan . Matematika Universitas Andalas. Jurnal Matematika UNAND, 6(1), 33. https://doi.org/10.25077/jmu.6.1.3341.2017

Muller, M. (2004). Goodness of fit criteria for survival data. Paper, 382. http://epub.ub.uni-muenchen.de/

Ratnaningsih, D. J., Saefuddin, A., Kurnia, A., \& Mangku, W. (2019). Survival modeling on non active students' study of Universitas Terbuka: A case study. Turkish Online Journal of Distance Education. https://doi.org/10.17718/tojde.522697

Sudana, I. G. A., Suciptawati, N. L. P., \& Ida Harini, L. P. (2013). Penerapan Regresi Cox Proportional Hazard Untuk Menduga Faktor-Faktor Yang Memengaruhi Lama Mencari Kerja. E-Jurnal Matematika, 2(3), 7. https://doi.org/10.24843/mtk.2013.v02.i03. p041
Verweij, P. J. M., van Houwelingen, H. C., \& Stijnen, T. (1998). A Goodness-of-Fit Test for Cox's Proportional Hazards Model Based on Martingale Residuals. Biometrics, 54(4), 1517. https://doi.org/10.2307/2533676 